\title{
Scientific evidence for sustainable plant disease protection strategies for the main arable crops in Sweden. A systematic map protocol
}

\author{
Anna Berlin ${ }^{1 *}$, Helena Nordström Källström², Anders Lindgren ${ }^{3}$ and Åke Olson ${ }^{1}$
}

\begin{abstract}
Background: Efficient and sustainable plant protection is of great economic and ecological significance for global crop production. A number of challenges, e.g. climate change, population growth and global trade, put increasing demands on future crop production and crop protection. This necessitates an increase in crop productivity with less environmental impact while maintaining good food quality and food security. To meet these challenges, it is essential that the recommendations provided to growers are efficient and correct, which can only be ensured by evidencebased recommendations based on outcomes from scientific studies.

Methods and output: The aim of these systematic maps is to compile scientific evidence for different plant disease protection strategies for the main arable crops grown in Sweden. Six major crops (wheat, barley, oat, potato, sugar beet and oilseed rape) have been selected based on the area under production, the annual production, the economic importance, and the amount of pesticide used against diseases in these crops in Sweden. All methods to manage diseases will be considered, including cropping system, pesticide application, biological control methods, as well as combinations of methods and integrated pest management. These systematic maps will only deal with field studies of relevance for agricultural practices in Sweden, although we expect that the results will be applicable for northern Europe as a whole. The main outcome to be used will be productivity measured as yield per area. Plant health and pathogen reduction will be included as a proxy for potential increase in crop quality and yield. This will provide a systematic overview of the plant disease protection measures that have been reported in the scientific literature. The study will result in one searchable database per crop that may be used as a catalogue of evidence for researchers and stakeholders, especially authorities and advisory organizations. The systematic maps will aid in the identification of areas that need further research and guide funding agencies and policymakers when deciding where research resources should be allocated. It will also help to select topics for future systematic reviews and meta-studies within the field of plant protection.
\end{abstract}

Keywords: Triticum aestivum, Hordeum vulgaris, Avena sativa, Solanum tuberosum, Brassica napus, Beta vulgaris, Temperate climate, Disease control

\footnotetext{
*Correspondence: Anna.Berlin@slu.se

1 Department of Forest Mycology and Plant Pathology, Swedish

University of Agricultural Sciences, Box 7026, Uppsala 750 07, Sweden

Full list of author information is available at the end of the article
} 


\section{Background}

The intensification of agriculture has to a large extent met the demand of feeding a growing population, but the increase in agricultural production has reached a plateau in many countries [1]. The increase in yields can partly be attributed to improved plant pest and disease management, including better understanding of the disease causing organisms and the use of a range of different control measures. Efficient and sustainable crop protection is of vast economic and ecological significance for food and feed production worldwide [2]. Future crop production faces a number of challenges, e.g. climate change, population growth and increased global trade [3, 4]. These challenges have already resulted in increased risks of establishment, spread and propagation of plant pests and pathogens $[5,6]$, potentially leading to unfavorable consequences for the environment and public health [7]. One of the greatest challenges is the development of resistance in pathogens towards pesticides, making the products less efficient or even inefficient. Current legislation aims to limit negative environmental impact of chemical control. As a result, several active substances in pesticides have been or will be prohibited for agricultural use, and thus development of alternative control strategies is crucial. Modern, efficient sustainable crop protection must provide the growers with tools to produce safe food of high quality and concurrently fulfill several environmental goals such as reduced climate impact, a non-toxic environment, good quality ground water and sustainable management of ecosystems [8].

Crop protection is a wide and complex topic that includes several research fields. Different interventions can be used to limit the impact of plant diseases, and crop protection measures are commonly used in all cropping systems. During the last century, research has led to significant increase in agricultural production, which to a large extent has relied on the introduction and use of agrochemicals. Until the 1940s, chemical treatments against plant diseases relied on inorganic chemical substances such as the "Bourdeaux mixture", a mixture of copper sulfate $\left(\mathrm{CuSO}_{4}\right)$ and slaked lime $\left(\mathrm{Ca}(\mathrm{OH})_{2}\right)$ [9]. Between the 1940s and 1970s, a range of effective organic compounds for managing plant diseases were developed and widely used. This created an over-reliance on chemical control. However, the use of pesticides is often a temporal solution, and several pathogens (and pests and weeds) have developed resistance, limiting the efficiency of their use [10]. Strategies to combine different methods that, alone, have limited efficiency can generate valuable synergies and limit the need of chemical control.

The EU directive on sustainable use of pesticides (2009/128/EC) promotes the application of Integrated Pest Management (IPM). The integration of several management methods are gathered under the eight principles of IPM [11]. These principles emphasize the production of a healthy crop with the least possible impact on the agro-ecosystem, and encourages the use of nonchemical control measures. The directive is now being implemented in all EU member states, however in Sweden and several other countries, IPM was applied already before the EU directive came into force. The scientific evidence necessary for developing IPM recommendations are similar between countries. To achieve the longterm goal of implementation of IPM, knowledge from many disciplines has to be combined, and researchers and practitioners with different experiences and backgrounds need to be involved $[12,13]$.

The agricultural crop production in Sweden faces several economic and ecological challenges. To meet these challenges, the growers need sound recommendations based on scientific results. The Swedish board of agriculture is a public authority, and its regional plant protection centers are key players in Swedish plant protection. The centers act as a link between research and implementation of pest and disease management, and they provide official recommendations for plant protection measures [14]. The information provided by the centers is commonly used by advisors and growers in decisions about control of diseases in commercial crop production. The official recommendations are updated annually and are based on a mixture of scientific evidence, field trial evaluations and practical experience. Recommendations on crop protection strategies are also provided by other organizations and private companies active in Sweden. To a large extent, these organizations utilize the recommendations compiled by the plant protection centers at the Swedish board of agriculture.

Plant protection strategies can be preventive, including crop rotation and cultivar selection, or direct with the use of pesticides or removal of diseased plants when an outbreak occurs. A decision to take any plant protection measure is based both on the risk of yield loss caused by a disease, and the grower's perception of the risk of missing a treatment, that could have been justified, against a disease. As an example, in many cases pesticide treatments are done unnecessarily, but are regarded as an insurance by the growers [19]. Scientifically based evidence in decision support for both preventive and direct plant protection measures could limit economically unjustified pesticide treatments and limit the negative impact of pesticides or other crop protection measures on the surrounding environment. Sustainable plant protection requires a joint effort among stakeholders such as advisors, growers, experts at authorities, and researchers. The development and improvement of molecular methods makes it possible to detect, identify and better 
understand the agents that cause plant diseases. In addition, the computer capacity to develop models for disease forecasting has significantly improved. Combined, the tools currently available should allow for improved plant disease management with less impact on the surrounding environment.

To provide high quality plant protection recommendations, a systematic review is a useful tool to objectively evaluate the evidence base. Systematic reviews are well established in the field of medicine, where they are used to minimize bias and allow a consensus to be made across the evidence base [15]. These types of assessments are less common in plant disease management where only a few systematic reviews [16] and some meta-analyses have been published [16-18]. A solid evidence base is important to allow for use of the best practice and knowledge in the recommendations in order to retain the crop producers' trust in plant protection advices. A systematic review is potentially a useful tool to underpin crop protection recommendations to growers. The evidence may lead to reduction in pesticide use that benefits the environment, increases profitability for crop producers and improves food security. A reduction in pesticide use would prolong the efficiency of different pesticides against disease causing agents that easily develop resistance against their active substances. A systematic map with a comprehensive literature overview is an important step towards more evidence based plant disease management and will help to identify subject areas suitable for systematic review or meta-analysis. The aim of these systematic maps is to perform an inventory of current knowledge and to identify future needs regarding plant disease management in the most important arable crops in Swedish agriculture. We expect to get an overview on the available scientific literature for different disease management strategies and interventions for the selected crops. The results from these systematic maps will also allow for future systematic reviews of specific topics within each of the selected crops.

\section{Topic identification}

The most common direct disease control measure currently available during the growing season is the use of pesticides. Many growers apply pesticide more or less routinely, which cannot always be economically justified. The reason behind this is the difficulty to handle the annual variation in net return from pesticide treatments [19], highlighting the decision making struggles that growers face. To be able to keep up with emerging new diseases and other threats to crop production, growers have to be flexible and able to adjust to future challenges and demands [20]. This underlines the need for an overview of which evidence are available to support sustainable crop production in relation to plant health. Systematic maps as well as systematic reviews, unlike traditional review articles, follow rigorous, objective and transparent processes that reduce bias in the selection of included studies and publications. The selection of literature is based on strict decision criteria regarding inclusion and appraisal, making reviews based on systematic searches transparent and readily understood. We therefore consider these systematic maps, one for each of the selected crops, to be a vital initiative to collect the scientific evidence on plant disease management, as a first step towards more evidence based advice and recommendations within disease management for agricultural practice.

\section{Objective of the systematic maps}

The overall aim is to make systematic maps for the main arable crops in Sweden and to provide an overview of which plant disease protection measures that have a sufficient volume of scientific literature for a systematic review and to identify where knowledge is missing. The maps can also be used to enable researchers to identify areas that need further studies and to guide policy makers when allocating research resources. The literature gathered in these systematic maps can support authorities and advisory service organizations when identifying methods for crop protection measures to be included in disease management recommendations to growers.

The crop selection was based on data indicating the importance of the crop in Swedish agriculture, i.e. the area under production of the crop, the total annual harvest, the economic importance (average price during the last 5 years), and the annual use of pesticides against diseases (http://www.scb.se). Based on these criteria, the six selected crops are wheat (Triticum aestivum), barley (Hordeum vulgare), oat (Avena sativa), potato (Solanum tuberosum), sugar beet (Beta vulgaris) and oilseed rape (Brassica napus).

The systematic maps will describe the volume and main characteristics of the scientific literature (the evidence base), and identify evidence clusters and knowledge gaps in the area of plant protection for each crop separately. One searchable database per crop will provide a catalogue of evidence for researchers and stakeholders, especially authorities and advisory organizations, which could be used for future studies and as a resource base when updating plant protection recommendations.

\section{Primary question}

What is the evidence base of plant disease protection measures and strategies available for the main arable crops of Sweden? This primary question will be divided into sub-questions, one for each of the six selected crops. 


\section{Components of the primary question Population}

The six selected crops previously described: Wheat (Triticum aestivum), barley (Hordeum vulgare), oat (Avena sativa), potato (Solanum tuberosum), sugar beet (Beta vulgaris) and oilseed rape (Brassica napus).

\section{Intervention}

Measures to control crop disease, including but not restricted to crop rotation, resistant cultivars, cultivar mixtures, ploughing, no-tillage, biological control, biofungicide and pesticide applications. Control measures will be considered individually or in combination.

\section{Comparator}

The primary comparison will be between an intervention and no intervention (control). Studies where different interventions are compared will also be included.

\section{Outcomes}

The measures of outcomes to be used will be productivity measured as yield per area, disease suppression and increase in crop quality. Plant health and pathogen reduction will also be included as a proxy for potential yield increase or increase in crop quality.

\section{Methods}

\section{Searching for publications}

The database search will be conducted in English but include Latin names of crop species. A time span restriction that includes literature published during the last 40 years (1978-2018) will be applied in the searches. Since the searches are based on English language, the results may be biased towards evidence from North America and Europe compared to if a broader search would be made.

\section{Bibliographic databases}

The following data will be recorded: date of search, database and platform name, institutional subscription used to access the database, search term, number of hits. The following academic citation databases will be searched for studies:

1. Web of Science Core Collection (http://webofknowl edge.com/WOS).

2. Biosis Citation Index (http://webofknowledge.com/ $\mathrm{BCI})$.

3. CABI: CAB Abstracts and Global Health (http:// webofknowledge.com/CABI).
4. Scopus (https://www.scopus.com/).

5. Agris (http://agris.fao.org/).

Database 1-3 are reached through the Swedish university of agricultural sciences subscription at Web of Sciences (v.5.30).

\section{Search strings}

A list of search terms relevant for the systematic maps were identified through discussions with both researchers and colleagues active in the field of plant pathology, and with persons in the advisory service at the Swedish board of agriculture. The search strategy has been optimized during the scoping phase, aiming to find an appropriate balance between sensitivity (collecting all relevant information) and specificity (the proportion of articles that are relevant) [21].

The search terms were combined into search strings using wild cards $(*)$ and connectors (AND and OR). The wildcard (*) allows to pick up multiple word endings e.g. Fung* would pick up fungi, fungal and fungus etc. Search terms will be combined using the operator AND (both terms must be present somewhere in the search field) and OR (at least one them have to be present in the search field). This allows us to structure our search terms according to thematic blocks: "Crop", "Disease causing organism", "Plant disease terms" and "Outcome". The distinct search terms for each thematic block were tested individually and in combination against Web of Science Core Collection (http://webofknowledge.com/ WOS) (Additional file 1: Table S1). The thematic block "crop", which consists of the common name combined with the Latin name of the crop, e.g. wheat OR "Triticum aestivum", will be combined with the search strings of the other three thematic blocks with the operator AND in the final searches (crop [block] AND disease causing organism [block] AND plant disease terms [block] AND outcome [block]). The full search strings of the three thematic blocks "disease causing organism", "plant disease terms" and "outcome" is presented in Table 1. The full search for all crop blocks were tested in the database Web of Science Core Collection (Table 2). Search results for wheat (Triticum aestivum) using the full search string in all databases are presented in Table 3. Each search will be performed for each of the selected crops separately, creating six sub-topics and resulting in six separate maps, one for each crop.

The results of each full string search from the selected database will be imported into a separate EndNote X9 library file, recording the number of references captured. Library files from each crop will be combined in one file each. Using an automatic duplicate identifier function in 
Table 1 Search strings for three thematic blocks

\begin{tabular}{|c|c|}
\hline Thematic block & Search string $^{a}$ \\
\hline Disease causing organism & Fung* OR oomycete* OR nematod* OR bacter* OR virus* OR viral OR viroid* OR pathogen* \\
\hline Plant disease terms & $\begin{array}{l}\text { "Disease incidence" OR "disease severity" OR "plant protection" OR "control strateg*" OR "risk } \\
\text { management" OR "biological control" OR "disease control" OR IPM OR "integrated pest } \\
\text { management" OR "plant defen*"OR resistance OR "disease develop*" }\end{array}$ \\
\hline Outcome & "Plant health" OR yield* OR qualit* OR harvest OR produc* OR "pathogen reduction" \\
\hline
\end{tabular}

a The search strings of each thematic block is combined with the operator AND for the final search

Table 2 Full search results for all six crops in Web of Science Core Collection 1978-2018

\begin{tabular}{lll}
\hline Crop & Date & Number of hits \\
\hline Wheat (Triticum aestivum) & $2018-10-08$ & 4.243 \\
Barley (Hordeum vulgare) & $2018-10-08$ & 1.646 \\
Oat (Avena sativa) & $2018-10-08$ & 334 \\
Potato (Solanum tuberosum) & $2018-10-08$ & 3.131 \\
Sugar beet (Beta vulgaris) & $2018-10-08$ & 566 \\
Oilseed rape (Brassica napus) & $2018-10-08$ & 517
\end{tabular}

Table 3 Full search for wheat (Triticum aestivum) in all databases (1978-2018)

\begin{tabular}{|c|c|c|}
\hline Database & Date & Number of hits \\
\hline Web of Science Core Collection & 2018-10-08 & 4.243 \\
\hline Biosis Citation Index ${ }^{\mathrm{a}}$ & 2018-10-08 & 2.242 \\
\hline CABI: CAB Abstracts and Global Health & 2018-10-08 & 12.095 \\
\hline Scopus & 2018-10-08 & 3.312 \\
\hline Agris $^{b}$ & 2018-10-08 & 1.451 \\
\hline
\end{tabular}

a (2009-2018)

b A shorter search string was used [(Fung* OR oomycete* OR nematod* OR bacter* OR virus* OR viral OR viroid* OR pathogen*) AND (wheat OR "Triticum aestivum")]

EndNote X9, all duplicated records will be highlighted. Identified duplicates will be removed after manual inspection and the number of removed references will be recorded.

\section{Specialist search for grey literature}

A search for grey literature (literature not issued by commercial academic publishers) will be performed to cover three sources; First, databases for pre-print archives such as bioRxiv (http://www.biorxiv.org), PeerJ (http://www. peerj.org) and arXiv (http://www.arxiv.org) will be used to identify pre-published research studies. Secondly, using the limited search string used for Agris (Table 3), an extensive title-only search of Google Scholar and a screening of the first 1000 records will be performed. Thirdly, webpages of the following relevant organizations will be searched. Swedish webpages will be search with both English and Swedish searched strings.

- Swedish board of agriculture (https://www.jordb ruksverket.se).

- RISE, Research Institute of Sweden AB (https://www. ri.se).

- SEGES, Landbrug \& Fødevarer F.m.b.A. (https:// www.seges.dk/en).

- NIBIO, Norwegian Institute of Bioeconomy Research (https://www.nibio.no/en).

- Norwegian Food Safety Authority (https://www. mattilsynet.no).

- Luke, Natural Resources Institute Finland (http:// www.luke.fi).

- Evira, Finnish Food Safety Authority (https://www. evira.fi).

- Federal Ministry of Food and Agriculture, Germany (https://www.bmel.de/).

- Rothamsted Research (https://www.rothamsted.ac. uk).

- Animal and Plant Health Agency, UK (https://www. gov.uk/government/organisations/animal-and-plant -health-agency).

- Agricultural and Horticulture Development Board in the UK (https://ahdb.org.uk).

- EPPO, European and Mediterranean Plant Protection Organization (https://www.eppo.int).

- EFSA, European Food Safety Authority (http://www. efsa.europa.eu).

- FAO, Food and Agricultural Organization of the United Nation (http://www.fao.org).

- INRA, French National Institute for Agricultural Research (http://institut.inra.fr/en).

- European Crop Protection Association (https://www. ecpa.eu).

- The World Bank (http://www.worldbank.org).

- CGIAR, Consultative Group for International Agricultural Research (https://www.cgiar.org).

- Swedish bachelor and master theses (https://www. uppsatser.se). 
- Swedish doctoral theses (https://www.avhandling ar.se).

\section{Article screening and study inclusion criteria Screening process}

All the articles identified through the searches will initially be screened by title (1) to remove all that are clearly not relevant for these systematic maps. That can be articles regarding medicine or studies reporting results from a climatic zone not relevant for Swedish agriculture. Secondly, articles will be evaluated at abstract (2) level for relevance using the predefined inclusion criteria (detail below). Articles not excluded at these levels, will be screened at the full text (3) level to ensure relevance. All articles excluded after step (1) and (2) will be recorded in one file and articles excluded at stage (3) will be recorded in another separate file and assigned a reason for exclusion. EndNote library files containing records of articles excluded at title and abstract levels will be supplied in additional files. A list of excluded studies at the full text level and reasons for exclusion will be recorded in an additional file.

To ensure consistency, a sub-set of 200 articles retrieved by the search for one of the selected crops will be checked against the inclusion criteria at title, abstract and full text levels by all reviewers independently. A kappa test will be used to determine agreement at the three different levels, with a score of 0.6 or above indicating substantial agreement. Any disagreement will be discussed, and any definition that require clarification will be adjusted accordingly. Reviewers that are authors of relevant articles will not be included in the decision connected to the inclusion and critical appraisal of their articles.

Reference lists in review articles will be screened to ensure that relevant primary research articles are included in our searches. References in reviews not identified in the database searches and fulfilling the inclusion criteria will be added to the systematic maps. The review articles as such will not be included. Due to the extent of the topic inclusion criteria, a coherent inclusion criterium strategy has been developed for all crops and will be used consistently for all searches. We will include all publications fulfilling the following conditions:

\section{Relevant population}

Articles that cover at least one of the selected crops, wheat (Triticum aestivum), barley (Hordeum vulgare), oat (Avena sativa), potato (Solanum tuberosum), sugar beet (Beta vulgaris) or oilseed rape (Brassica napus).
Articles based on field trials in a geographical region with relevant climate for Swedish agriculture. This inclusion criterion will be based on the Köppen-Geiger climate classification zones [22]. Studies from temperate regions in zone $\mathrm{Cfb}$ and $\mathrm{Dfb}$, corresponding to the main agricultural areas of southern Sweden and Dfc, corresponding to northern Sweden will be included. Studies from regions in climate zone $\mathrm{Cfa}$, will also be included since several of the grain producing areas in the world, such as eastern North and South America, east China and Japan, east Australia and New Zealand are located in this type of climate.

\section{Relevant intervention}

Articles that report about any disease management intervention, independently or in combination, including but not limited to crop rotation, resistant cultivars, cultivar mixtures, ploughing, no-tillage, biological control, biofungicide and pesticide applications will be included.

\section{Relevant outcome}

Articles that report any type of effect of disease control interventions that are measured in productivity in terms of total harvest, yield per area or relevant crop quality measures e.g. decrease in toxin levels, plant health status or reduced disease symptoms. Pathogen reduction will also be included as a proxy for potential yield increase or increase in crop quality.

\section{Relevant study design}

Before and after studies (BA), before and after control impact studies (BACI), randomized control trials (RCT) randomized split block trials (RSBT) and exposure versus no exposures/control impact (CI).

We will exclude all articles not accessible as full-text in English and articles based on studies performed in laboratory or glass houses as well as potted plant experiments. Studies including pesticide or chemical substances that are not registered for use against plant diseases in EU will also be removed. For this, a list of active substances allowed for use in the EU will be retrieved from the European Commission online database (https://ec.europa.eu/ food/plant/pesticides_en) at the start of the study. Studies that do not address the primary question but help to put the collated evidence into context regarding current control strategies of plant diseases will be recorded in a separate file to help analyze the result. When in doubt about the relevance of an article, the article will be included.

\section{Data coding strategy}

Standardized descriptive data from all studies meeting the inclusion criteria will be stored in Excel spreadsheet, which will form the systematic maps. Data from each study will be coded as follows: 


\section{Study information}

Bibliographic information:

Crop:

Climatic zone:

Location of study:

Disease:

Pathogen type:

Disease causing organism:

Study type:

Intervention:

Management:

Diseased part(s):

Plant stage/age:

Outcome:
Unique reference ID, Reference type, Year of publication, Authors, Title, Journal, Volume, Page number, URL or DOI Wheat, barley, oat, potato, sugar beet, or oilseed rape $\mathrm{Cfa}, \mathrm{Cfb}, \mathrm{Dfb}$, or Dfc Countries, or regions when relevant

Name of diseases (listed in Additional file 2)

Fungi, bacteria, viruses, viroids, virus-like organisms, phytoplasmas, protozoa, oomycetes, nematodes, or parasitic plants

Scientific names of organisms (listed in Additional file 2)

Before/after (BA), Before and after control impact (BACI), Randomized control trial (RCT), Randomized split block trials (RSBT), or Exposure versus no exposure/control impact $(\mathrm{CI})$

Application of any type of pesticide or biological control agent, removal of diseased plants or plant parts etc.

Agricultural practices such as crop rotation, ploughing or no tillage etc.

Seed, root, tuber, leaf, straw, ear, or flower

Plantlet/seedling, adult, mature, or post-harvest

Yield, crop quality, toxin, plant health, disease incidence, or disease severity

\section{Critical appraisal and study quality assessment}

A full critical appraisal of included studies will not be carried out in these systematic maps because the breadth of the topic and the wide variety of studies included would make this complex and difficult. A basic quality assessment of the study design during data coding will be undertaken and a brief description in the form of a "free text" of the quality of the included studies can be made when considered informative.

\section{Systematic map presentations}

All included studies and their meta-data will be recorded in a searchable Excel database that will be made available with the published systematic map reports, as an additional supporting file. The accompanying report will describe the review process, the amount and nature of available scientific base in text and in graphs and figures, knowledge gaps and gluts that were identified. Based on the findings, the report will also include recommendations.

\section{Additional files}

Additional file 1: Table S1. Record of individual search terms for wheat (Triticum aestivum) in Web of Science Core Collection. Search conducted 2018-06-20.

Additional file 2. Lists of plant pathogens and diseae names in English and Swedish for each crop.

Authors' contributions

$\AA \mathrm{O}, \mathrm{AB}$ and $\mathrm{HNK}$ planned the project, $\mathrm{AB}$ were main responsible for writing the manuscript, $\AA \mathrm{O}$ performed the searches, all authors discussed and commented on the manuscript. All authors read and approved the final manuscript.

\section{Author details}

${ }^{1}$ Department of Forest Mycology and Plant Pathology, Swedish University of Agricultural Sciences, Box 7026, Uppsala 750 07, Sweden. ${ }^{2}$ Department of Urban and Rural Development, Swedish University of Agricultural Sciences, Box 7012, Uppsala 750 07, Sweden. ${ }^{3}$ Plant Protection Centre, Swedish Board of Agriculture, Kungängsvägen 19 A, Uppsala 753 23, Sweden.

Acknowledgements

We would like to acknowledge Björn Andersson and Annika Djurle for constructive comments on the text and Jonas Törngren for assistance.

Competing interests

The authors declare that they have no competing interests.

Availability of data and materials

All material will be provided upon request. 


\section{Consent for publication}

All authors agree with the publication of this paper.

\section{Ethics approval and consent to participate}

No ethical approval was necessary for this study.

\section{Funding}

FORMAS special call "National research program for food -First call: syntheses within the food area" Grant Number 2017-02028.

\section{Publisher's Note}

Springer Nature remains neutral with regard to jurisdictional claims in published maps and institutional affiliations.

Received: 2 July 2018 Accepted: 1 December 2018

Published online: 15 December 2018

\section{References}

1. Bommarco R, Kleijn D, Potts SG. Ecological intensification: harnessing ecosystem services for food security. Trends Ecol Evol. 2013;28(4):230-8.

2. Flood J. The importance of plant health to food security. Food Secur. 2010;2(3):215-31.

3. Sundström JF, Albihn A, Boqvist S, Ljungvall K, Marstorp H, Martiin C, et al. Future threats to agricultural food production posed by environmental degradation, climate change, and animal and plant diseasesa risk analysis in three economic and climate settings. Food Secur. 2014;6(2):201-15.

4. Chakraborty S, Newton AC. Climate change, plant diseases and food security: an overview. Plant Pathol. 2011;60(1):2-14.

5. Barnwal MK, Kotasthane A, Magculia N, Mukherjee PK, Savary S, Sharma AK, et al. A review on crop losses, epidemiology and disease management of rice brown spot to identify research priorities and knowledge gaps. Eur J Plant Pathol. 2013;136(3):443-57.

6. Cheatham MR, Rouse MN, Esker PD, Ignacio S, Pradel W, Raymundo R, et al. Beyond yield: plant disease in the context of ecosystem services. Phytopathology. 2009;99(11):1228-36.

7. Savary S, Bregaglio S, Willocquet L, Gustafson D, Mason D'Croz D, Sparks A, et al. Crop health and its global impacts on the components of food security. Food Secur. 2017;9(2):311-27.

8. McKenzie FC, Williams J. Sustainable food production: constraints, challenges and choices by 2050. Food Security. 2015;7(2):221-33.
9. Russell PE. A century of fungicide evolution. J Agric Sci. 2005;143(1):11-25.

10. van den Bosch F, Paveley N, Fraaije B, van den Berg F, Oliver R. Evidencebased resistance management: a review of existing evidence. In: Ishii $\mathrm{H}$, Hollomon DW, editors. Fungicide resistance in plant pathogens: principles and a guide to practical management. Japan, Tokyo: Springer; 2015. p. 63-76.

11. Barzman M, Bàrberi P, Birch ANE, Boonekamp P, Dachbrodt-Saaydeh S, Graf B, et al. Eight principles of integrated pest management. Agron Sustain Dev. 2015;35(4):1199-215.

12. Giles KL, McCornack BP, Royer TA, Elliott NC. Incorporating biological control into IPM decision making. Curr Opin Insect Sci. 2017;20:84-9.

13. Gregory PJ, Johnson SN, Newton AC, Ingram JS. Integrating pests and pathogens into the climate change/food security debate. J Exp Bot. 2009;60(10):2827-38.

14. Jordbruksverket, Bekämpningsrekommendationer Svampar och insekter 2018, L. Eds Eriksson, Editor. 2018, Jordbruksverket: www.jordbruksverket .se/bekampningsrek. p. 124.

15. Haddaway NR, Bernes C, Jonsson BG, Hedlund K. The benefits of systematic mapping to evidence-based environmental management. Ambio. 2016;45(5):613-20.

16. Ngugi HK, Esker PD, Scherm H. Meta-analysis to determine the effects of plant disease management measures: review and case studies on soybean and apple. Phytopathology. 2010;101(1):31-41.

17. Rosenberg MS, Garrett KA, Su Z, Bowden RL. Meta-analysis in plant pathology: synthesizing research results. Phytopathology. 2004;94(9):1013-7.

18. Scherm H, Thomas CS, Garrett KA, Olsen JM. Meta-analysis and other approaches for synthesizing structured and unstructured data in plant pathology. Annu Rev Phytopathol. 2014;52(1):453-76.

19. Djurle A, Twengström $E$, Andersson B. Fungicide treatments in winter wheat: the probability of profitability. Crop Prot. 2018;106:182-9.

20. Shiferaw B, Smale M, Braun HJ, Duveiller E, Reynolds M, Muricho G. Crops that feed the world 10. Past successes and future challenges to the role played by wheat in global food security. Food Secur. 2013;5:291-317.

21. James KL, Randall NP, Haddaway NR. A methodology for systematic mapping in environmental sciences. Environ Evid. 2016;5(1):7.

22. Kottek M, Griesner J, Beck C, Rudolf B, Rubel F. World Map of the Köppen-Geiger climate classification updated. Meterologische Zeitscrift. 2006;15(3):259-63.
Ready to submit your research? Choose BMC and benefit from:

- fast, convenient online submission

- thorough peer review by experienced researchers in your field

- rapid publication on acceptance

- support for research data, including large and complex data types

- gold Open Access which fosters wider collaboration and increased citations

- maximum visibility for your research: over 100M website views per year

At BMC, research is always in progress.

Learn more biomedcentral.com/submissions 